\title{
BMJ Open Long-term exposure to traffic-related air pollution and progression of carotid artery atherosclerosis: a prospective cohort study
}

\author{
Wen Qi Gan, ${ }^{1,2}$ Ryan W Allen, ${ }^{3}$ Michael Brauer, ${ }^{4}$ Hugh W Davies, ${ }^{4}$ \\ G B John Mancini, ${ }^{5,6}$ Scott A Lear ${ }^{3,7,8}$
}

To cite: Gan WQ, Allen RW, Brauer $\mathrm{M}$, et al. Long-term exposure to traffic-related air pollution and progression of carotid artery atherosclerosis: a prospective cohort study. BMJ Open 2014;4:e004743.

doi:10.1136/bmjopen-2013004743

- Prepublication history and additional material is available. To view these files please visit the journal (http://dx.doi.org/10.1136/ bmjopen-2013-004743).

Received 27 December 2013 Revised 25 February 2014 Accepted 3 March 2014

CrossMark

For numbered affiliations see end of article.

Correspondence to Dr Wen Qi Gan; wgan@nshs.edu

\section{ABSTRACT}

Objectives: Epidemiological studies have demonstrated associations between long-term exposure to trafficrelated air pollution and coronary heart disease (CHD). Atherosclerosis is the principal pathological process responsible for $\mathrm{CHD}$ events, but effects of traffic-related air pollution on progression of atherosclerosis are not clear. This study aimed to investigate associations between long-term exposure to traffic-related air pollution and progression of carotid artery atherosclerosis.

Setting: Healthy volunteers in metropolitan Vancouver, Canada.

Participants and outcome measures: 509 participants aged 30-65 years were recruited and followed for approximately 5 years. At baseline and end of follow-up, participants underwent carotid artery ultrasound examinations to assess atherosclerosis severity, including carotid intima-media thickness, plaque area, plaque number and total area. Annual change of each atherosclerosis marker during the follow-up period was calculated as the difference between these two measurements divided by years of follow-up. Living close to major roads was defined as $\leq 150 \mathrm{~m}$ from a highway or $\leq 50 \mathrm{~m}$ from a major road. Residential exposures to traffic-related air pollutants including black carbon, fine particles, nitrogen dioxide and nitric oxide were estimated using high-resolution land-use regression models. The data were analysed using general linear models adjusting for various covariates.

Results: At baseline, there were no significant differences in any atherosclerosis markers between participants living close to and those living away from major roads. After follow-up, the differences in annual changes of these markers between these two groups were small and not statistically significant. Also, no significant associations were observed with concentrations of traffic-related air pollutants including black carbon, fine particles, nitrogen dioxide and nitric oxide.

Conclusions: This study did not find significant associations between traffic-related air pollution and progression of carotid artery atherosclerosis in a region with lower levels and smaller contrasts of ambient air pollution.

\section{Strengths and limitations of this study}

This study utilised multiple markers, including carotid intima-media thickness, plaque area, plaque number, and total area, to assess carotid artery atherosclerosis. Exposure to traffic-related air pollution was assessed using residential proximity to major roads and spatially resolved estimates of residential exposure to black carbon, fine particles, nitrogen dioxide and nitric oxide.

- This study simultaneously investigated crosssectional and longitudinal associations between exposure to traffic-related air pollution and carotid artery atherosclerosis in a large metropolitan area with relatively low levels of air pollution.

- Compared with previous longitudinal studies, this study has a relatively long follow-up period (median 5.4 years, range 3.7-7.2 years).

- Small sample size, moderate progression of atherosclerosis in the study sample, along with lower levels and smaller contrasts of ambient air pollution in the study region, might limit our ability to detect presumably small effects of air pollution on progression of carotid artery atherosclerosis in this study.

\section{INTRODUCTION}

Convincing epidemiological evidence has demonstrated that long-term exposure to ambient air pollution is associated with cardiovascular disease, especially coronary heart disease (CHD), morbidity and mortality. ${ }^{1}$ Although the biological mechanisms underlying the associations are not fully understood, it is well known that atherosclerosis is the principal pathological process responsible for chronic and acute CHD events. ${ }^{2-4}$ Atherosclerosis is a chronic condition characterised by a progressive buildup of plaques in the large arteries, which may cause chronic ischaemia due to insufficient blood supply and acute cardiac events due to plaque 
rupture and blood clot. ${ }^{2}{ }^{3}$ Epidemiological studies have shown that the severity of atherosclerosis measured by carotid intima-media thickness (CIMT) is able to predict future cardiovascular risk (eg, CHD and stroke) for people without cardiovascular diseases. ${ }^{5-7}$

It has been hypothesised that particulate air pollution is associated with cardiovascular outcomes through two major pathways: promoting atherosclerosis progression and triggering acute cardiac events in individuals with severe atherosclerosis, especially vulnerable plaques. ${ }^{3} 8$ Short-term exposure studies have provided sufficient evidence to support acute triggering effects of particulate air pollution. ${ }^{1}$ Long-term exposure studies based on clinical outcomes presumably integrate atherosclerosis progression and acute triggering effects, and thus have greater effect sizes than short-term exposure studies. However, these studies are unable to distinguish these two different adverse effects of particulate air pollution. ${ }^{18}$ Evidence is needed to determine the role of particulate air pollution on progression of atherosclerosis. ${ }^{8}$

Experimental studies in animals with risk factors for atherosclerosis have provided some evidence that exposure to particulate air pollution is associated with accelerated progression of atherosclerosis. ${ }^{9}{ }^{10}$ However, there is limited epidemiological evidence in humans to corroborate these findings. Several cross-sectional studies have examined associations of atherosclerosis severity with residential proximity to road traffic and exposure to fine particulate air pollution, but their findings were not fully consistent. ${ }^{11-15}$ Two recent longitudinal studies conducted in the USA have provided limited evidence to support an association between particulate air pollution and progression of atherosclerosis. ${ }^{16}{ }^{17}$ As suggested by Kunzli $e t a l,^{8}$ it is necessary to further investigate the relationship between long-term air pollution exposure and progression of atherosclerosis.

Air pollution is a complex mixture of particles, gases and liquids, mainly derived from the combustion of fossil fuels. ${ }^{18}$ In metropolitan areas, road traffic is a major source of ambient air pollution, and produces strong spatial gradients in pollution concentrations. ${ }^{19}$ It has been demonstrated that the concentrations of traffic-related air pollutants decrease exponentially from major roadways and approach background concentrations within about $150 \mathrm{~m}^{20}{ }^{21}$ Therefore, the distance from each person's residence to a major roadway may be used as a convenient surrogate for exposure to traffic-related air pollution. ${ }^{22} \mathrm{We}$ have previously demonstrated in a large population-based cohort study conducted in metropolitan Vancouver, Canada, that residential proximity to road traffic and traffic-related fine particulate air pollution (black carbon) were associated with increased risk of CHD hospitalisation and mortality. ${ }^{23-25}$

On the basis of the previous studies, we used a longitudinal study design to investigate the associations between progression of carotid artery atherosclerosis and longterm exposure to traffic-related air pollution, indicated by residential proximity to major roads and residential concentrations of four major traffic-related air pollutants including black carbon, particulate matter $<2.5 \mu \mathrm{m}$ in aerodynamic diameter $\left(\mathrm{PM}_{2.5}\right)$, nitrogen dioxide $\left(\mathrm{NO}_{2}\right)$ and nitric oxide $(\mathrm{NO})$, in metropolitan Vancouver.

\section{MATERIALS AND METHODS}

\section{Participants and study design}

The current study was based on the Multicultural Community Health Assessment Trial (M-CHAT), which was designed to compare body fat distribution in different ethnic groups. The M-CHAT study design has been described in detail elsewhere. ${ }^{26}{ }^{27}$ During 2004-2005, 829 apparently healthy volunteers aged 30-65 years and matched for body mass index (BMI) and ethnicity (Aboriginal, Chinese, European and South Asian) were recruited in metropolitan Vancouver. During recruitment, individuals with the following characteristics were excluded: (1) having a prior diagnosis of cardiovascular disease or significant comorbidity such as diabetes or hypertension; (2) taking medications that affect cardiovascular risk factors such as lipid-lowering, antihypertensive or hypoglycaemic medications; (3) experiencing recent weight change more than $2.2 \mathrm{~kg}$ within recent 3 months and (4) having significant prosthetics or amputations.

The participants were followed for approximately 5 years. Each participant underwent carotid artery ultrasound examinations to assess severity of atherosclerosis at baseline (2004-2005) and the end of follow-up (20092011). Residential proximity to major roads and exposures to traffic-related air pollutants were estimated based on participants' residential addresses at baseline. Various potential confounding factors were collected through standard questionnaires that were administered by trained interviewers. General linear models were used to examine cross-sectional and longitudinal associations of carotid artery atherosclerosis with residential traffic proximity and four major traffic-related air pollutants after adjustment for various potential confounding factors including residential exposure to community noise.

\section{Exposure assessment}

\section{Residential proximity to major roads}

Residential proximity to major roads was estimated based on participants' geocoded baseline residential addresses using a geographic information system (GIS). In DMTI ArcView street file dataset for British Columbia (Canmap Streetfiles, V.2006.3; DMTI Spatial, Markham, Ontario, Canada), road types in the study region were divided into two categories: highway (DMTI type 1 and 2 roads) including expressway (average traffic counts 114000 vehicles/day) and principal highway (21 000 vehicles/day), or major road (DMTI type 3 and 4 roads) including secondary highway (18 000 vehicles/day) and major road (15 000 vehicles/day). Based on the differences in traffic volumes between highways and major roads,${ }^{28}$ and the previous findings that the concentrations of traffic-related air pollutants decrease exponentially from major roads 
and approach background concentrations within about $150 \mathrm{~m},{ }^{20}{ }^{21}$ participants in the current study were divided into two groups: those living close to major roads, defined as $\leq 150 \mathrm{~m}$ from a highway or $\leq 50 \mathrm{~m}$ from a major road; and those living away from major roads.

\section{Air pollution exposure assessment}

The air pollution exposure assessment has been described in detail elsewhere. ${ }^{29-31}$ High-resolution (10 m) land-use regression (LUR) models were developed in the study region to estimate annual average concentrations for four major traffic-related air pollutants, including black carbon, $\mathrm{PM}_{2.5}, \mathrm{NO}_{2}$ and NO. The performance of the models was evaluated using the coefficient of determination $\left(\mathrm{R}^{2}\right)$ and estimated mean error $( \pm \mathrm{SD})$ from leave-one-out cross validation analysis (black carbon: $\mathrm{R}^{2}=0.56$, mean error $=0$ $\pm 0.23 \times 10^{-5} / \mathrm{m} ; \mathrm{PM}_{2.5}: \mathrm{R}^{2}=0.52$, mean error $=0 \pm 1.50 \mu \mathrm{g} / \mathrm{m}^{3}$; $\mathrm{NO}_{2}: \mathrm{R}^{2}=0.56$, mean error $=0 \pm 5.2 \mu \mathrm{g} / \mathrm{m}^{3} ; \mathrm{NO}: \mathrm{R}^{2}=0.62$, mean error $=2.02 \pm 15.5 \mu \mathrm{g} / \mathrm{m}^{3}$ ). The predictors and performance of these LUR models have been discussed in detail previously. ${ }^{24}$ The LUR models were developed in 2003, and we have recently shown that the spatial patterns of traffic-related air pollution in Vancouver remained stable between 2003 and 2010. ${ }^{32}$ The air pollution data were assigned to participants through their baseline residential addresses to approximate individual exposure to these traffic-related air pollutants.

\section{Carotid artery atherosclerosis assessment}

The assessment method for carotid artery atherosclerosis has been described in detail elsewhere. ${ }^{27} 33$ High-resolution B-mode ultrasonography equipped with a $10 \mathrm{MHz}$ linear array transducer was used. A uniform length of $10 \mathrm{~mm}$ in the far wall of the common carotid artery within $2 \mathrm{~cm}$ proximal to the carotid bulb was selected for manual measurement of intima-media thickness (IMT). In the selected area, the largest IMT without focal lesions was measured; the average of the largest IMT in the left and right carotid arteries was calculated as a person's CIMT. Plaque was defined as any focal protrusion above the surrounding intima; plaque number was counted in each carotid segment including common, internal, external carotid arteries and carotid bulb for two carotid arteries. The area of a single plaque was calculated as the average lesion thickness $(\mathrm{mm})$ multiplied by the lesion length $(\mathrm{mm})$; and plaque area was calculated as the sum of the area of each plaque $\left(\mathrm{mm}^{2}\right)$. Total area $\left(\mathrm{mm}^{2}\right)$ was calculated as the sum of plaque area and IMT area measured in the left and right carotid arteries; IMT area $\left(\mathrm{mm}^{2}\right)$ was calculated as the average IMT $(\mathrm{mm})$ multiplied by the length $(20 \mathrm{~mm})$ over which the IMT was measured. These four atherosclerosis markers were included as outcome variables in the current study, because they are related to cardiovascular risk factors and are able to predict future cardiovascular events. ${ }^{5-7} 3334$

To evaluate the reproducibility of the measurement, 192 randomly selected participants from the cohort had the measurements repeated by different technicians.
The average difference between two measurements was $0.3 \mu \mathrm{m}$ for CIMT, $0.39 \mathrm{~mm}^{2}$ for plaque area and $0.13 \mathrm{~mm}^{2}$ for total area. The differences were small and not statistically significant.

\section{Potential confounding factors}

The following were important cardiovascular risk factors and were regarded as potential confounding factors in our analyses: age, sex (male or female), ethnicity (Aboriginal, Chinese, European or South Asian), BMI, cigarette smoking status (never, former or current smoker), educational attainment ( $\leq$ high school or $>$ high school), annual household income $(<\$ 30000, \$ 30000$ to $\$ 60000$, or $\geq \$ 60000$ ), leisure time physical activity (hours per week), systolic blood pressure (SBP), diastolic blood pressure (DBP), low-density lipoprotein cholesterol (LDL-C), highdensity lipoprotein cholesterol (HDL-C) and total cholesterol. In the analysis for traffic-related air pollutants, community noise was also treated as a potential confounding factor. $^{25}$

The demographic and behavioural risk factors were collected through standard questionnaires, which were administered by trained interviewers. Leisure time physical activity was estimated based on average minutes each week spent in physical activity during the previous year. Blood pressure was measured using an automated oscillometric office blood pressure monitor (VSM MedTech Ltd, Coquitlam, Canada). After $10 \mathrm{~min}$ of seated rest, five successive measurements were recorded; average SBP and DBP were calculated by averaging these five readings. Meanwhile, fasting blood samples were collected to measure LDL-C, HDL-C and total cholesterol using standard enzymatic procedures in the same clinical laboratory. ${ }^{27}$ Residential exposure to community noise (annual day-evening-night A-weighted equivalent continuous noise levels, $\mathrm{L}_{\mathrm{den}} \mathrm{dB}(\mathrm{A})$ ) was estimated based on baseline residential addresses and surrounding transportation information including road width, speed limits, traffic volume and fleet composition. ${ }^{35}$

Neighbourhood socioeconomic status was assessed using neighbourhood income quintiles and neighbourhood education quintiles derived from the 2006 Statistics Canada Census data. Neighbourhood income quintiles were calculated using the medians of household income in the dissemination areas of the study region. Neighbourhood education quintiles were calculated using the percentages of people with certificate, diploma or degree in the dissemination areas of the study region. ${ }^{23}$

\section{Statistical analyses}

Baseline characteristics of participants were compared between the group living close to and the group living away from major roads using a $\chi^{2}$ test for categorical variables, two-sample t test for normally distributed continuous variables, and Wilcoxon two-sample test for skewed continuous variables. Correlations between pollutants were examined using Spearman's rank correlation analysis. 
General linear models were used to compare carotid atherosclerosis levels between these two groups. Annual change for each atherosclerosis marker during the follow-up period was calculated as the difference between these two measurements (end of follow-up minus baseline) divided by the number of years of follow-up. Adjusted differences of atherosclerosis levels between these two groups were calculated using the group living away from major roads as the reference category. In addition, we performed two sensitivity analyses for progression of atherosclerosis. First, we repeated the above analyses for participants with increased severity of atherosclerosis indicated by each atherosclerosis marker (annual change $>0$ ). Second, we used the 85th centile of annual change of each atherosclerosis marker as the cut-off point to identify participants with greater progression of atherosclerosis (events). The Cox proportional hazard models were used to calculate relative risks of having greater progression of atherosclerosis for participants living close to major roads compared with those living away from major roads. In the Cox models, person-years were calculated for each participant from the date of baseline examination to the date of follow-up examination.

To examine independent associations between residential traffic proximity and carotid artery atherosclerosis, statistical analyses were performed to control for various potential confounding variables through four models: model 1 was a crude unadjusted model; model 2 was adjusted for age (continuous), sex and ethnicity; model 3 was further adjusted for BMI (continuous), smoking status, leisure time physical activity (continuous), educational attainment and annual household income in addition to the covariates included in model 2; model 4 was further adjusted for SBP (continuous), LDL-C (continuous), HDL-C (continuous), neighbourhood income quintiles, and neighbourhood education quintiles in addition to the covariates included in model 3 . In the analyses for the associations between traffic-related air pollutants and progression of carotid artery atherosclerosis, we calculated differences of annual changes for each atherosclerosis marker in relation to an IQR elevation in each traffic-related air pollutant after adjustment for community noise and those covariates included in model 4.

All statistical tests were two-sided and were performed using SAS, V.9.3 (SAS Institute Inc, Cary, North Carolina, USA).

\section{RESULTS}

A total of 829 participants were recruited at baseline. Thirteen individuals did not perform the carotid ultrasound examination, and 56 individuals did not provide accurate residential addresses and thus could not be geocoded; these individuals were excluded, leaving 760 participants (92\% of those recruited) with complete data at baseline. Among these participants, 509 completed the follow-up, with a follow-up rate of $67 \%$, median follow-up time of 5.4 years (range 3.7-7.2 years). Compared with those lost to follow-up, participants who completed follow-up had higher socioeconomic status (eg, better education, higher annual household income) and better health profiles (eg, more never smokers, lower BMI and waist circumference); however, there were no significant differences between the two groups in the baseline carotid artery atherosclerosis (see online Tables 1 and 2).

Baseline annual average concentrations of traffic-related air pollutants and annual average levels of community noise are summarised in table 1 . Overall, air pollution and community noise levels were not strongly correlated; also, air pollutants were not strongly correlated with each other, with the exception of $\mathrm{NO}$ and $\mathrm{NO}_{2}$ (table 1). These results are consistent with those of our previous studies performed in the study region.

At baseline, $117(23 \%)$ participants lived close to major roads. As expected, these participants were exposed to higher levels of traffic-related air pollutants and community noise compared with those living away from major roads (table 1); furthermore, these participants had lower annual household income, were more likely to be Aboriginal and less likely to be of South Asian origin. There were no substantial differences between these two groups with respect to age, sex,

Table 1 Baseline average concentrations of traffic-related air pollutants, average levels of community noise and correlation

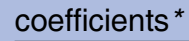

\begin{tabular}{|c|c|c|c|c|c|c|c|c|c|c|c|}
\hline \multirow[b]{2}{*}{ Pollutant } & \multirow{2}{*}{$\begin{array}{l}\text { Mean (SD) } \\
\text { (close to } \\
\text { major roads)† }\end{array}$} & \multirow{2}{*}{$\begin{array}{l}\text { Mean (SD) } \\
\text { (away from } \\
\text { major roads) } ¥\end{array}$} & \multirow{2}{*}{ Mean (SD) } & \multirow[b]{2}{*}{ Median } & \multirow[b]{2}{*}{ IQR } & \multirow[b]{2}{*}{ Range } & \multicolumn{5}{|c|}{ Correlation coefficient } \\
\hline & & & & & & & BC & $\mathrm{PM}_{2.5}$ & $\mathrm{NO}_{2}$ & NO & Noise \\
\hline $\mathrm{BC}\left(10^{-5} / \mathrm{m}\right) \S$ & $3.03(1.60)$ & $1.24(0.71)$ & $1.65(1.24)$ & 1.08 & $0.89-1.90$ & $0.0-5.00$ & 1.00 & - & - & - & - \\
\hline $\mathrm{PM}_{2.5}\left(\mu \mathrm{g} / \mathrm{m}^{3}\right)$ & $4.27(1.54)$ & $4.03(1.42)$ & $4.08(1.45)$ & 4.09 & $3.40-4.81$ & $0.0-10.00$ & 0.13 & 1.00 & - & - & - \\
\hline $\mathrm{NO}_{2}\left(\mu \mathrm{g} / \mathrm{m}^{3}\right)$ & $19.1(4.2)$ & $16.6(3.9)$ & $17.2(4.1)$ & 16.5 & $14.6-18.7$ & $7.9-30.0$ & 0.38 & 0.45 & 1.00 & - & - \\
\hline $\mathrm{NO}\left(\mu \mathrm{g} / \mathrm{m}^{3}\right)$ & $39.0(15.7)$ & $24.1(6.7)$ & $27.6(11.4)$ & 24.9 & $20.5-31.3$ & $8.4-100.0$ & 0.51 & 0.43 & 0.73 & 1.00 & - \\
\hline Noise $(\mathrm{dB}(\mathrm{A}))$ & $73.9(6.2)$ & $65.4(5.3)$ & $67.4(6.6)$ & 65.3 & $63.2-71.8$ & $37.1-83.4$ & 0.40 & 0.19 & 0.28 & 0.41 & 1.00 \\
\hline
\end{tabular}


education, BMI, smoking status, alcohol intake, physical activity, blood pressure and blood lipids (table 2).

At baseline, compared with those living away from major roads, participants living close to major roads had similar levels of carotid atherosclerosis measured by CIMT, plaque area, plaque number and total area. After adjustment for various potential confounding factors in models $2-4$, there were no significant differences between these two groups in these atherosclerosis markers (table 3).

After 5 years of follow-up, atherosclerosis levels were increased for most participants (see online Table 3). Overall, the mean values of annual changes for these atherosclerosis markers were similar between these two groups; the differences in annual changes of these markers between these two groups were small and not statistically significant after adjustment for various potential confounding factors in models 2-4 (table 4). When the analyses were repeated for participants with increased atherosclerosis indicated by each single marker, the results were similar to those presented in table 4 (see online Table 4); when the 85th centile of annual change of each marker was used to identify participants with greater progression, the risk of having greater progression was not significantly different between these two groups (see online Table 5). Similarly, there were no significant associations between annual changes in these atherosclerosis markers and traffic-related air pollutants, including black carbon, $\mathrm{PM}_{2.5}, \mathrm{NO}_{2}$ and $\mathrm{NO}$, after adjustment for various potential confounding factors including residential exposure to community noise (table 5 ). There were no substantial differences between the results from the final models with and without community noise.

The stratified analyses show that atherosclerosis effects associated with exposure to road traffic were stronger for participants with the following characteristics: male, Chinese and South Asian background, higher family income, obesity and never smokers (table 6 ). The results for some strata (eg, age $\geq 60$ years) were not completely consistent across different atherosclerosis markers.

\section{DISCUSSION}

In this longitudinal study with over 5 years of follow-up, we did not find significant associations between residential exposure to traffic-related air pollution and carotid artery atherosclerosis in either cross-sectional or

Table 2 Baseline characteristics of participants stratified by traffic proximity*

\begin{tabular}{|c|c|c|c|c|}
\hline Characteristic & $\begin{array}{l}\text { All participants } \\
(n=509)\end{array}$ & $\begin{array}{l}\text { Close to major } \\
\text { roads }(n=117)\end{array}$ & $\begin{array}{l}\text { Away from major } \\
\text { roads }(n=392)\end{array}$ & p Valuet \\
\hline Age (year) & $46.8 \pm 9.0$ & $47.2 \pm 9.2$ & $46.7 \pm 8.9$ & 0.581 \\
\hline Sex, male (\%) & 49 & 51 & 49 & 0.593 \\
\hline Race (\%) & & & & 0.008 \\
\hline Aboriginal & 14 & 22 & 12 & \\
\hline Chinese & 30 & 32 & 29 & \\
\hline European & 29 & 27 & 30 & \\
\hline South Asian & 27 & 19 & 29 & \\
\hline Education (\%) & & & & 0.589 \\
\hline$\leq$ High school & 27 & 29 & 27 & \\
\hline$>$ High school & 73 & 71 & 73 & \\
\hline Annual household income (\%) & & & & 0.019 \\
\hline$<\$ 30000$ & 24 & 29 & 22 & \\
\hline$\$ 30000$ to $\$ 60000$ & 37 & 43 & 35 & \\
\hline$\geq \$ 60000$ & 39 & 28 & 43 & \\
\hline Smoke status (\%) & & & & 0.357 \\
\hline Current & 7 & 9 & 6 & \\
\hline Former & 27 & 24 & 28 & \\
\hline Never & 66 & 67 & 66 & \\
\hline Alcohol intake (yes, \%) & 32 & 30 & 32 & 0.649 \\
\hline Physical activity (hours per week) $\ddagger$ & $\begin{array}{l}3.5 \\
(1.7-6.5)\end{array}$ & $\begin{array}{l}2.9 \\
(1.6-6.5)\end{array}$ & $\begin{array}{l}1.3 \\
(0.9-1.8)\end{array}$ & 0.258 \\
\hline Body mass index $\left(\mathrm{kg} / \mathrm{m}^{2}\right)$ & $27.2 \pm 4.7$ & $27.5 \pm 4.3$ & $27.1 \pm 4.8$ & 0.459 \\
\hline $\mathrm{SBP}(\mathrm{mm} \mathrm{Hg})$ & $118 \pm 15$ & $117 \pm 14$ & $118 \pm 15$ & 0.357 \\
\hline $\mathrm{DBP}(\mathrm{mm} \mathrm{Hg})$ & $77 \pm 9$ & $77 \pm 10$ & $77 \pm 9$ & 0.826 \\
\hline Total cholesterol (mmol/L) & $5.2 \pm 1.0$ & $5.2 \pm 1.1$ & $5.3 \pm 1.0$ & 0.667 \\
\hline LDL-C (mmol/L) & $3.2 \pm 0.9$ & $3.2 \pm 0.9$ & $3.3 \pm 0.9$ & 0.311 \\
\hline HDL-C (mmol/L) & $1.3 \pm 0.4$ & $1.3 \pm 0.4$ & $1.3 \pm 0.4$ & 0.637 \\
\hline
\end{tabular}


Table 3 Cross-sectional mean differences $(95 \%$ Cls) in baseline carotid artery atherosclerosis between the group close to and the group away from major road (the reference category)

\begin{tabular}{|c|c|c|c|c|c|c|}
\hline Atherosclerosis & $\begin{array}{l}\text { Close to major } \\
\text { roads }(n=117)^{*}\end{array}$ & $\begin{array}{l}\text { Away from major } \\
\text { roads }(n=392)^{\star}\end{array}$ & $\begin{array}{l}\text { Difference†‡ } \\
\text { (model 1) }\end{array}$ & $\begin{array}{l}\text { Difference†‡ } \\
\text { (model 2) }\end{array}$ & $\begin{array}{l}\text { Difference†‡ } \\
\text { (model 3) }\end{array}$ & $\begin{array}{l}\text { Difference†‡ } \\
\text { (model 4) }\end{array}$ \\
\hline CIMT $(\mu \mathrm{m})$ & $664 \pm 125$ & $673 \pm 118$ & $-9.37(-35.24$ to 16.49$)$ & $-12.78(-35.32$ to 9.76$)$ & $-13.76(-36.17$ to 8.64$)$ & $-8.7(-31.15$ to 13.75$)$ \\
\hline Plaque area $\left(\mathrm{mm}^{2}\right)$ & $5.37 \pm 8.10$ & $6.62 \pm 11.85$ & $-1.25(-3.65$ to 1.14$)$ & $-1.62(-3.89$ to 0.66$)$ & $-1.45(-3.74$ to 0.85$)$ & $-0.88(-3.19$ to 1.43$)$ \\
\hline Plaque number & $0.83 \pm 0.93$ & $0.90 \pm 1.19$ & $-0.07(-0.31$ to 0.18$)$ & $-0.12(-0.36$ to 0.12$)$ & $-0.11(-0.35$ to 0.13$)$ & $-0.05(-0.29$ to 0.19$)$ \\
\hline Total area $\left(\mathrm{mm}^{2}\right)$ & $18.6 \pm 9.0$ & $20.1 \pm 13.0$ & $-1.45(-4.08$ to 1.18$)$ & $-1.88(-4.3$ to 0.54$)$ & $-1.73(-4.17$ to 0.71$)$ & $-1.07(-3.51$ to 1.38$)$ \\
\hline
\end{tabular}

\section{*Data are presented as mean $+\mathrm{SD}$.}

†Difference of least square means between the group close to and the group away from major roads (the group away from major roads was the reference category).

¥Model 1 was a crude unadjusted model; model 2 was adjusted for age, sex and ethnicity; model 3 was further adjusted for BMI, smoking status, physical activity, education and annual

household income; model 4 was additionally adjusted for systolic blood pressure, LDL-C, HDL-C, neighbourhood income levels and neighbourhood education levels.

BMI, body mass index; CIMT, carotid intima-media thickness; HDL-C, high-density lipoprotein cholesterol; LDL-C, low-density lipoprotein cholesterol.

Table 4 Mean differences $(95 \% \mathrm{Cls})$ in annual changes of carotid artery atherosclerosis between the group close to and the group away from major road (the reference category)

\begin{tabular}{|c|c|c|c|c|c|c|}
\hline Atherosclerosis & $\begin{array}{l}\text { Close to major } \\
\text { roads }(n=117)^{*}\end{array}$ & $\begin{array}{l}\text { Away from major } \\
\text { roads }(n=392)^{\star}\end{array}$ & $\begin{array}{l}\text { Difference†‡ } \\
\text { (model 1) }\end{array}$ & $\begin{array}{l}\text { Difference†‡ } \\
\text { (model 2) }\end{array}$ & $\begin{array}{l}\text { Difference†‡ } \\
\text { (model 3) }\end{array}$ & $\begin{array}{l}\text { Difference†‡ } \\
\text { (model 4) }\end{array}$ \\
\hline CIMT ( $\mu \mathrm{m} / \mathrm{year})$ & $8.93 \pm 10.57$ & $9.41 \pm 12.29$ & $-0.49(-3.07$ to 2.09$)$ & $-1.01(-3.62$ to 1.61$)$ & $-1.02(-3.66$ to 1.63$)$ & $-0.78(-3.49$ to 1.92$)$ \\
\hline Plaque area (mm²/year) & $35 \pm 2.72$ & 25 & $9(-0.42$ to 0.6$)$ & $0.03(-0.46$ to 0.5 & $0.03(-0.46$ to 0.53$)$ & $0.07(-0.42$ to 0.57$)$ \\
\hline Plaque number (per year) & $0.14 \pm 0.21$ & $0.13 \pm 0.20$ & $0.02(-0.03$ to 0.06$)$ & $0.01(-0.03$ to 0.05$)$ & $0.01(-0.04$ to 0.05$)$ & $0.01(-0.04$ to 0.05$)$ \\
\hline Total area $\left(\mathrm{mm}^{2} /\right.$ year $)$ & $1.52 \pm 2.79$ & $1.43 \pm 2.30$ & $0.09(-0.43$ to 0.61$)$ & $0.03(-0.47$ to 0.53$)$ & $0.03(-0.47$ to 0.54$)$ & $0.08(-0.43$ to 0.59$)$ \\
\hline
\end{tabular}

\section{*Data are presented as mean+SD.}

†Difference of least squares means between the group close to and the group away from major roads (the group away from major roads was the reference category).

¥Model 1 was a crude unadjusted model; model 2 was adjusted for age, sex and ethnicity; model 3 was further adjusted for BMI, smoking status, physical activity, education and annual

household income; model 4 was additionally adjusted for systolic blood pressure, LDL-C, HDL-C, neighbourhood income levels and neighbourhood education levels.

BMI, body mass index; CIMT, carotid intima-media thickness; HDL-C, high-density lipoprotein cholesterol; LDL-C, low-density lipoprotein cholesterol. 


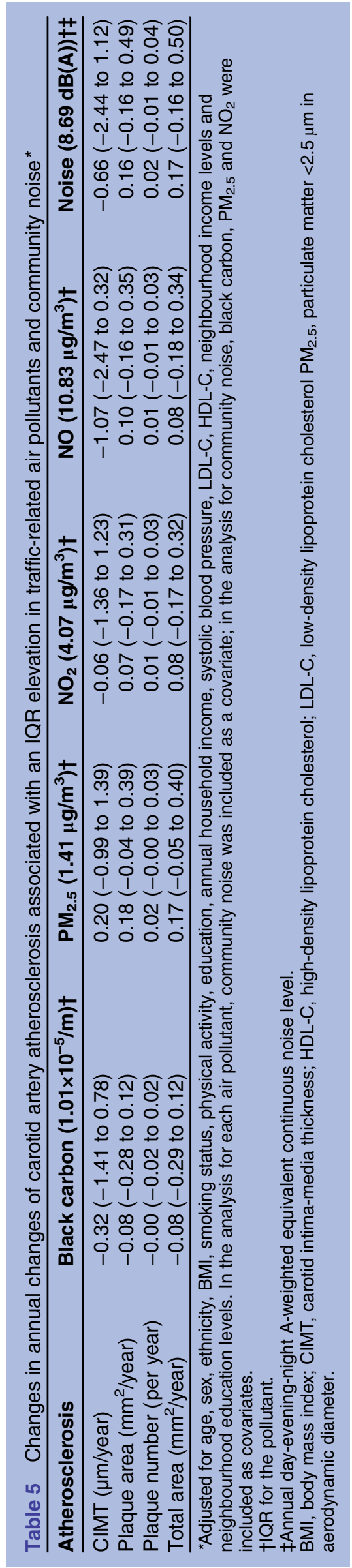

longitudinal analyses. Our results were largely consistent for various markers of carotid artery atherosclerosis including CIMT, plaque area, plaque number and total area and for various traffic exposure indicators including residential traffic proximity, black carbon, $\mathrm{PM}_{2.5}, \mathrm{NO}_{2}$ and NO. This study has several strengths including its longitudinal study design, the relatively long follow-up period, multiple markers of carotid artery atherosclerosis, various traffic exposure indicators and control for various potential confounding factors in the statistical analyses.

As measurement error in the ultrasound examination of carotid atherosclerosis might have prevented detection of very subtle effects of air pollution on carotid atherosclerosis, we performed two sensitivity analyses by restricting analyses to participants with increased atherosclerosis and by using the 85th centile of annual change of each marker to identify participants with greater progression of atherosclerosis. The results of these sensitivity analyses are similar to those observed in the main analyses, suggesting that the null associations were less likely due to measurement error in atherosclerosis assessment. For those covariates included in the final models, age, sex, race and LDL-C levels were each significantly associated with progression of carotid artery atherosclerosis indicated by plaque area, plaque number and total area. There were no significant associations of carotid artery atherosclerosis with BMI, smoking, physical activity or blood pressure. Notably, we did not find any significant associations of CIMT with established cardiovascular risk factors. As mentioned before, our study participants were young (30-65 years) and healthy (eg, they did not have comorbid conditions); these factors might partly explain the null associations.

Compared with the two recent longitudinal studies (see online Table 6) by Adar et $a l^{16}$ and Kunzli et al, ${ }^{17}$ our study is different in the following four aspects: (1) on an average, our participants were more than 10 years younger (baseline mean age 47 years vs 62 and 59 years); (2) the study region had lower levels and smaller contrasts of ambient $\mathrm{PM}_{2.5}$ (baseline annual mean concentration $4.1 \mu \mathrm{g} / \mathrm{m}^{3}$ vs 16.6 and $27.8 \mu \mathrm{g} / \mathrm{m}^{3}$; IQR $1.4 \mu \mathrm{g} / \mathrm{m}^{3}$ vs 2.5 and $1.7 \mu \mathrm{g} / \mathrm{m}^{3}$ ); (3) our participants did not have comorbid conditions such as diabetes and hypertension at baseline and (4) the current study took into account the potential influences of community noise on the associations between traffic-related air pollutants and progression of carotid artery atherosclerosis. These differences may partly explain the null associations in our study. Overall, our baseline CIMT $(673 \pm 122 \mu \mathrm{m})$ and annual change in CIMT $(9.2 \pm 12.1 \mu \mathrm{m} /$ year $)$ were comparable with those by Adar et al ${ }^{16}(678 \pm 189 \mu \mathrm{m}, 14.0 \pm 53.0 \mu \mathrm{m} /$ year), but were quite different from those of Kunzli et $a l^{17}$ $(780 \pm 150 \mu \mathrm{m}, 2.0 \pm 12.9 \mu \mathrm{m} /$ year $)$; perhaps because the former is based on a multiethnic sample, similar to our study, whereas the latter was based on the data from five clinical trials.

It should be noted that the findings of the two recent longitudinal studies were not entirely consistent. ${ }^{16}{ }^{17}$ 
Table 6 Mean differences (95\% Cls) in annual changes of carotid artery atherosclerosis between the group close to and the group away from major road (the reference category)*

\begin{tabular}{|c|c|c|c|c|}
\hline & CIMT $(\mu \mathrm{m})$ & Plaque area $\left(\mathrm{mm}^{2}\right)$ & Plaque number & Total area $\left(\mathrm{mm}^{2}\right)$ \\
\hline \multicolumn{5}{|l|}{ Age (years) } \\
\hline$<60$ & $-0.76(-3.59$ to 2.08$)$ & $0.01(-0.51$ to 0.53$)$ & $0.00(-0.05$ to 0.05$)$ & $0.02(-0.51$ to 0.56$)$ \\
\hline$\geq 60$ & $1.38(-11.27$ to 14.02$)$ & $-0.18(-2.53$ to 2.17$)$ & $0.02(-0.18$ to 0.23$)$ & $-0.16(-2.52$ to 2.19$)$ \\
\hline \multicolumn{5}{|l|}{ Sex } \\
\hline Men & $1.29(-2.81$ to 5.39$)$ & $0.22(-0.64$ to 1.07$)$ & $0.00(-0.07$ to 0.07$)$ & $0.24(-0.63$ to 1.12$)$ \\
\hline Women & $-1.97(-5.69$ to 1.75$)$ & $-0.06(-0.57$ to 0.45$)$ & $0.01(-0.04$ to 0.07$)$ & $-0.07(-0.59$ to 0.45$)$ \\
\hline \multicolumn{5}{|l|}{ Race } \\
\hline Aboriginal & $-2.41(-9.48$ to 4.66$)$ & $0.81(-0.36$ to 1.99$) \dagger$ & $0.04(-0.12$ to 0.20$)$ & $0.77(-0.43$ to 1.97$) \dagger$ \\
\hline Chinese & $0.89(-4.67$ to 6.45$)$ & $1.12(0.21$ to 2.03$) \dagger$ & $0.08(0.00$ to 0.16$)$ & $1.21(0.30$ to 2.12$) \dagger$ \\
\hline European & $-2.80(-7.97$ to 2.37$)$ & $-1.86(-3.06$ to -0.65$) \dagger$ & $-0.10(-0.19$ to 0.00$)$ & $-1.92(-3.16$ to -0.68$) \dagger$ \\
\hline South Asian & $1.18(-5.44$ to 7.79$)$ & $0.29(-0.53$ to 1.12$) \dagger$ & $0.02(-0.07$ to 0.1$)$ & $0.32(-0.54$ to 1.17$) \dagger$ \\
\hline \multicolumn{5}{|c|}{ Annual household income } \\
\hline$<\$ 30000$ & $-1.67(-7.78$ to 4.44$)$ & $-0.07(-0.98$ to 0.85$)$ & $0.04(-0.04$ to 0.12$)$ & $-0.10(-1.04$ to 0.84$)$ \\
\hline$\$ 30000$ to $\$ 60000$ & $-2.86(-6.84$ to 1.11$)$ & $-0.20(-0.84$ to 0.44$)$ & $-0.01(-0.08$ to 0.06$)$ & $-0.19(-0.84$ to 0.45$)$ \\
\hline$\geq \$ 60000$ & $1.99(-3.39$ to 7.37$)$ & $0.61(-0.48$ to 1.7$)$ & $0.00(-0.08$ to 0.09$)$ & $0.65(-0.47$ to 1.77$)$ \\
\hline \multicolumn{5}{|l|}{ Education } \\
\hline$\leq$ High school & $2.57(-3.05$ to 8.20$)$ & $-1.01(-1.91$ to -0.11$) \dagger$ & $-0.05(-0.13$ to 0.04$)$ & $-0.92(-1.82$ to -0.02$)$ \\
\hline >High school & $-1.60(-4.81$ to 1.61$)$ & $0.49(-0.12$ to 1.10$) \dagger$ & $0.02(-0.03$ to 0.07$)$ & $0.46(-0.17$ to 1.09$)$ \\
\hline \multicolumn{5}{|c|}{ Obesity $\left(\mathrm{BMI} \geq 30 \mathrm{~kg} / \mathrm{m}^{2}\right)$} \\
\hline No & $-1.24(-4.34$ to 1.85$)$ & $-0.05(-0.60$ to 0.49$)$ & $0.01(-0.04$ to 0.06$)$ & $-0.04(-0.60$ to 0.51$)$ \\
\hline Yes & $1.81(-4.94$ to 8.56$)$ & $0.60(-0.81$ to 2.00$)$ & $0.05(-0.06$ to 0.17$)$ & $0.64(-0.80$ to 2.07$)$ \\
\hline \multicolumn{5}{|l|}{ Smoke status } \\
\hline Current & $-9.58(-26.66$ to 7.50$)$ & $-1.20(-4.94$ to 2.54$)$ & $-0.09(-0.45$ to 0.28$)$ & $-1.41(-5.29$ to 2.47$)$ \\
\hline Former & $-1.92(-7.89$ to 4.05$)$ & $-0.52(-1.60$ to 0.55$)$ & $-0.01(-0.11$ to 0.09$)$ & $-0.56(-1.66$ to 0.54$)$ \\
\hline Never & $0.30(-3.14$ to 3.73$)$ & $0.24(-0.38$ to 0.86$)$ & $0.00(-0.06$ to 0.05$)$ & $0.27(-0.36$ to 0.90$)$ \\
\hline
\end{tabular}

Adar et al found that a $2.5 \mu \mathrm{g} / \mathrm{m}^{3}$ increase in $\mathrm{PM}_{2.5}$ was associated with a $5.0 \mu \mathrm{m}(95 \%$ CI 2.6 to $7.4 \mu \mathrm{m})$ annual increase in CIMT; however, the association was observed for within-but not between-city contrasts. ${ }^{16}$ Kunzli et $a l^{17}$ reported that a $10 \mu \mathrm{g} / \mathrm{m}^{3}$ elevation in $\mathrm{PM}_{2.5}$ was associated with a non-significant $2.5 \mu \mathrm{m}(95 \%$ CI -0.3 to $5.4 \mu \mathrm{m})$ annual increase in CIMT; however, living close to a major roadway was associated with a $5.5 \mu \mathrm{m}(95 \%$ CI 0.13 to $10.79 \mu \mathrm{m}$ ) annual increase in CIMT compared with those living away from a major roadway. In addition, the findings of previous cross-sectional studies were also not consistent. Kunzli et $a l^{11}$ reported a positive but nonsignificant association between $\mathrm{PM}_{2.5}$ and CIMT using the baseline data from two clinical trials in Los Angeles. Based on the MESA air baseline data, Diez Roux et al ${ }^{12}$ found that $\mathrm{PM}_{2.5}$ was associated with CIMT, but no significant association was observed with coronary artery calcification; Allen et $a l^{13}$ found that aortic calcification was associated with $\mathrm{PM}_{2.5}$ among participants with longterm residence, but no significant association was observed with residential traffic proximity. Based on the baseline data from a German study conducted in Ruhr area, Hoffmann et $a l^{14}$ found that traffic proximity, but not $\mathrm{PM}_{2.5}$, was associated with coronary artery calcification; whereas Bauer et $a l^{15}$ found that $\mathrm{PM}_{2.5}$, but not traffic proximity, was associated with CIMT. Using data from the Atherosclerosis Risk in Young Adults study, Lenters $e t a l^{36}$ did not find any associations of CIMT with air pollutants $\left(\mathrm{PM}_{2.5}\right.$, black smoke, $\left.\mathrm{NO}_{2}, \mathrm{SO}_{2}\right)$ and traffic indicators (traffic proximity, traffic density). ${ }^{36}$ In a randomised, double-blind, placebo controlled trial on the association between cigarette smoking and progression of CIMT, Johnson et $a l^{37}$ did not find a significant association between cigarette smoking and progression of CIMT. Recently, in a panel study with 380 participants, Wilker $e t a l^{88}$ found that a $0.26 \mu \mathrm{g} / \mathrm{m}^{3}$ (IQR) increase in black carbon concentrations was associated with a $1.1 \%$ increase in CIMT (95\% CI 0.4 to $1.7 \%$ ). Also, several recent cross-sectional studies have consistently found significant associations of CIMT with biomass fuel ${ }^{39}$ and traffic-related air pollution. ${ }^{40}{ }^{41}$ In the current study, we did not find significant associations of CIMT or other atherosclerosis markers with traffic proximity and traffic-related air pollution. The findings of these studies suggest that inconsistencies are existent within and between different studies on the relationship between ambient air pollution and severity of atherosclerosis, and that CIMT is not necessarily an ideal marker to reflect adverse cardiovascular effects associated with environmental exposure. 
There are some limitations in our study that might have potentially affected the study results. Residential proximity to road traffic is a convenient but crude surrogate for residential exposure to traffic-related air pollution. First, geocoding of residential addresses in a GIS might have introduced positional error. ${ }^{42}$ Given the sharp concentration gradients of traffic-related air pollution near major roads, the positional error might have introduced some exposure misclassification. Second, residential traffic proximity did not take into account environmental factors that might have affected actual residential exposure such as wind direction, street canyons, ${ }^{43}$ housing characteristics, ${ }^{44}$ and indoor infiltration of air pollutants. ${ }^{45}$ Third, although residential exposure is able to reasonably reflect personal exposure, ${ }^{46}{ }^{47}$ individual factors such as time spent at home, outdoor activity and occupational exposure might have affected actual personal exposure. Fourth, our exposure assessment was based on participants' baseline residential addresses, we did not have residential history information during the follow-up period. Exposure misclassification might have occurred for those who changed their residences and therefore their exposure status. Overall, all these factors would be expected to cause nondifferential exposure misclassification, reducing our ability to uncover the true relationship between traffic-related air pollution and carotid artery atherosclerosis.

Loss to follow-up was another limitation of the current study. $33 \%$ of participants were lost to follow-up, leaving a relatively small sample of 509 individuals. Overall, participants who completed follow-up had higher socioeconomic status and better health profiles compared with those lost to follow-up. Therefore loss to follow-up, in combination with the relatively small sample size, might potentially contribute to the null associations in our study. Finally, after the first ultrasound examination of carotid atherosclerosis, it was possible that some participants might have taken medications (eg, statins) that were able to reduce progression of atherosclerosis. ${ }^{48} \mathrm{We}$ did not have information on medication use during the follow-up period. Nevertheless, as mentioned before, we did exclude persons who took relevant medications at baseline. Also, this was a group of healthy people who did not have cardiovascular diseases or comorbid conditions. Therefore, they were less likely to take medications such as statins during the follow-up period.

Furthermore, this study has a smaller sample size compared with two recently reported cohort studies. ${ }^{16} 17$ However, some previous studies with small sample sizes are still able to detect significant associations of CIMT with black carbon $(\mathrm{N}=380)^{38}$ and residential traffic proximity ( $\mathrm{N}=777$ in a subgroup). ${ }^{17}$ Based on these studies, it was possible for our study ( $\mathrm{N}=509)$ to detect a significant association between traffic-related air pollution and carotid artery atherosclerosis if the association was really existent in the population.

As discussed before, in the study region, the air pollution levels were low (annual mean $\mathrm{PM}_{2.5}$ concentration $4.1 \mu \mathrm{g} / \mathrm{m}^{3}$ ) and the exposure contrast was relatively small (IQR $1.4 \mu \mathrm{g} / \mathrm{m}^{3}$ ), which may have played an important role in the null associations with atherosclerosis markers. Finally, the measurement of CIMT was based on the average of the largest IMT without focal lesions in the specified areas. Because the largest thickness area at baseline might potentially progress to become a focal lesion during the follow-up period, the second CIMT measure at the end of follow-up might be smaller than the baseline measure, leading to artificially decreased CIMT. Nevertheless, this is not a major problem because other larger thickness areas at baseline might potentially progress to become the largest IMT without focal lesions at the end of follow-up. Also, this type of progression of atherosclerosis could be reflected by plaque number, plaque area and total area.

The stratified analyses (table 6) show considerable heterogeneity in effect estimates across different atherosclerosis markers. Because of very small sample sizes in these subgroups, it is difficult to determine whether the heterogeneity was due to chance (small sample size) or reflected real effects. Nevertheless, it was notable that the obese group (versus the non-obese group), the never-smoking group (versus current/former smoking group), and Chinese or South Asian background (versus European background) consistently had larger effect estimates across different atherosclerosis markers.

As aforementioned, in a population-based cohort study conducted in the same study region and using the same exposure metrics ${ }^{23}$ we found that residential proximity to road traffic was associated with an increased risk of CHD mortality, whereas changes in traffic proximity were associated with altered risk of coronary mortality within a relatively short period of time. Moving closer to major roads was associated with increased risk, whereas moving away from major roads was associated with decreased risk. These previous findings, in conjunction with the null associations between traffic proximity and carotid artery atherosclerosis in the current study, indicate that triggering of acute cardiac events might play an important role in the associations between traffic-related air pollution and cardiovascular outcomes.

\section{Conclusions}

In this 5-year longitudinal study, we did not find significant associations between residential exposure to traffic-related air pollution and progression of carotid artery atherosclerosis in a region with relatively low levels and small contrasts of air pollution. Because the findings of previous studies are not fully consistent, more research is needed to determine the relationship between longterm exposure to traffic-related air pollution and progression of atherosclerosis.

\section{Author affiliations}

${ }^{1}$ Department of Population Health, Hofstra North Shore-LIJ School of Medicine, Great Neck, New York, USA

${ }^{2}$ Feinstein Institute for Medical Research, North Shore-Long Island Jewish Health System, Great Neck, New York, USA 
${ }^{3}$ Faculty of Health Sciences, Simon Fraser University, Burnaby, British Columbia, Canada

${ }^{4}$ School of Population and Public Health, University of British Columbia, Vancouver, British Columbia, Canada

${ }^{5}$ Healthy Heart Program, St Paul Hospital, Providence Healthcare, Vancouver, British Columbia, Canada

${ }^{6}$ Faculty of Medicine, Division of Cardiology, University of British Columbia, Vancouver, British Columbia, Canada

${ }^{7}$ Department of Biomedical Physiology and Kinesiology, Simon Fraser University, Burnaby, British Columbia, Canada

${ }^{8}$ Division of Cardiology, Providence Health Care, Vancouver, British Columbia, Canada

Contributors All the authors contributed to the study conception and design. SAL, MB, RWA, HWD, GBJM contributed to the data collection. WQG analysed the data and was responsible for the accuracy of the data analysis. WQG wrote the first draft of the manuscript, all authors critically revised the manuscript for important intellectual content. All the authors have read and approved the final version of the manuscript.

Funding This research received no specific grant from any funding agency in the public, commercial or not-for-profit sectors.

Competing interests None.

Patient consent Obtained.

Ethics approval The study protocol was approved by the Simon Fraser University Research Ethics Board, and all participants provided informed consent.

Provenance and peer review Not commissioned; externally peer reviewed.

Data sharing statement No additional data are available.

Open Access This is an Open Access article distributed in accordance with the Creative Commons Attribution Non Commercial (CC BY-NC 3.0) license, which permits others to distribute, remix, adapt, build upon this work noncommercially, and license their derivative works on different terms, provided the original work is properly cited and the use is non-commercial. See: http:// creativecommons.org/licenses/by-nc/3.0/

\section{REFERENCES}

1. Brook RD, Rajagopalan S, Pope CA III, et al. Particulate matter air pollution and cardiovascular disease: an update to the scientific statement from the American Heart Association. Circulation 2010;121:2331-78.

2. Lusis AJ. Atherosclerosis. Nature 2000;407:233-41.

3. Libby $\mathrm{P}$, Theroux P. Pathophysiology of coronary artery disease. Circulation 2005;111:3481-8.

4. Ross R. The pathogenesis of atherosclerosis: a perspective for the 1990s. Nature 1993;362:801-9.

5. Chambless LE, Heiss G, Folsom AR, et al. Association of coronary heart disease incidence with carotid arterial wall thickness and major risk factors: the Atherosclerosis Risk in Communities (ARIC) Study, 1987-1993. Am J Epidemiol 1997;146:483-94.

6. Stein JH, Korcarz CE, Hurst RT, et al. Use of carotid ultrasound to identify subclinical vascular disease and evaluate cardiovascular disease risk: a consensus statement from the American Society of Echocardiography Carotid Intima-Media Thickness Task Force. Endorsed by the Society for Vascular Medicine. J Am Soc Echocardiogr 2008;21:93-111.

7. Chambless LE, Folsom AR, Clegg LX, et al. Carotid wall thickness is predictive of incident clinical stroke: the Atherosclerosis Risk in Communities (ARIC) study. Am J Epidemiol 2000;151:478-87.

8. Kunzli N, Perez L, von Klot S, et al. Investigating air pollution and atherosclerosis in humans: concepts and outlook. Prog Cardiovasc Dis 2011;53:334-43.

9. Sun $Q$, Wang $A$, Jin $X$, et al. Long-term air pollution exposure and acceleration of atherosclerosis and vascular inflammation in an animal model. JAMA 2005;294:3003-10.

10. Suwa T, Hogg JC, Quinlan KB, et al. Particulate air pollution induces progression of atherosclerosis. J Am Coll Cardiol 2002;39:935-42.

11. Kunzli N, Jerrett M, Mack WJ, et al. Ambient air pollution and atherosclerosis in Los Angeles. Environ Health Perspect 2005;113:201-6.
12. Diez Roux AV, Auchincloss AH, Franklin TG, et al. Long-term exposure to ambient particulate matter and prevalence of subclinical atherosclerosis in the Multi-Ethnic Study of Atherosclerosis. Am J Epidemiol 2008;167:667-75.

13. Allen RW, Criqui MH, Diez Roux AV, et al. Fine particulate matter air pollution, proximity to traffic, and aortic atherosclerosis. Epidemiology 2009;20:254-64.

14. Hoffmann B, Moebus S, Mohlenkamp S, et al. Residential exposure to traffic is associated with coronary atherosclerosis. Circulation 2007;116:489-96.

15. Bauer M, Moebus S, Mohlenkamp S, et al. Urban particulate matter air pollution is associated with subclinical atherosclerosis: results from the HNR (Heinz Nixdorf Recall) study. J Am Coll Cardiol 2010;56:1803-8.

16. Adar SD, Sheppard L, Vedal S, et al. Fine particulate air pollution and the progression of carotid intima-medial thickness: a prospective cohort study from the multi-ethnic study of atherosclerosis and air pollution. PLoS Med 2013;10:e1001430.

17. Kunzli N, Jerrett M, Garcia-Esteban R, et al. Ambient air pollution and the progression of atherosclerosis in adults. PLOS ONE 2010;5: e9096.

18. Brook RD, Franklin B, Cascio $\mathrm{W}$, et al. Air pollution and cardiovascular disease: a statement for healthcare professionals from the Expert Panel on Population and Prevention Science of the American Heart Association. Circulation 2004;109:2655-71.

19. Health Effects Institute. Traffic-related air pollution: A critical review of the literature on emissions, exposure, and health effects. http:// pubs.healtheffects.org/getfile.php? $u=553$

20. Zhu Y, Hinds WC, Kim S, et al. Concentration s C and size distribution of ultrafine particles near a major highway. J Air Waste Manag Assoc 2002;52:1032-42.

21. Zhou Y, Levy Jl. Factors influencing the spatial extent of mobile source air pollution impacts: a meta-analysis. BMC Public Health 2007;7:89

22. Jerrett $M$, Arain $A$, Kanaroglou $P$, et al. A review and evaluation of intraurban air pollution exposure models. J Expo Anal Environ Epidemiol 2005;15:185-204.

23. Gan WQ, Tamburic L, Davies HW, et al. Changes in residential proximity to road traffic and the risk of death from coronary heart disease. Epidemiology 2010;21:642-9.

24. Gan WQ, Koehoorn M, Davies HW, et al. Long-term exposure to traffic-related air pollution and the risk of coronary heart disease hospitalization and mortality. Environ Health Perspect 2011;119:501-7.

25. Gan WQ, Davies HW, Koehoorn M, et al. Association of long-term exposure to community noise and traffic-related air pollution with coronary heart disease mortality. Am J Epidemiol 2012;175:898-906.

26. Lear SA, Birmingham CL, Chockalingam A, et al. Study design of the Multicultural Community Health Assessment Trial (M-CHAT): a comparison of body fat distribution in four distinct populations. Ethn Dis 2006;16:96-100.

27. Lear SA, Humphries $\mathrm{KH}$, Kohli S, et al. Visceral adipose tissue, a potential risk factor for carotid atherosclerosis: results of the Multicultural Community Health Assessment Trial (M-CHAT). Stroke 2007;38:2422-9.

28. Brauer M, Hystad PW, Reynolds C. Develop with care 2012: Environmental guidelines for urban and rural land development in British Columbia. Supporting information - air quality. http://www. env.gov.bc.ca/wld/documents/bmp/devwithcare2012/DWC-AirQuality.pdf

29. Henderson SB, Beckerman B, Jerrett M, et al. Application of land use regression to estimate long-term concentrations of traffic-related nitrogen oxides and fine particulate matter. Environ Sci Technol 2007; 41:2422-8.

30. Larson T, Henderson SB, Brauer M. Mobile monitoring of particle light absorption coefficient in an urban area as a basis for land use regression. Environ Sci Technol 2009;43:4672-8.

31. Brauer M, Lencar C, Tamburic L, et al. A cohort study of traffic-related air pollution impacts on birth outcomes. Environ Health Perspect 2008;116:680-6.

32. Wang RR, Henderson SB, Sbihi $\mathrm{H}$, et al. Temporal stability of land use regression models for traffic-related air pollution. Atmos Environ 2013;64:312-19.

33. Aminbakhsh A, Frohlich J, Mancini GB. Detection of early atherosclerosis with $B$ mode carotid ultrasonography: assessment of a new quantitative approach. Clin Invest Med 1999;22:265-74.

34. Chan SY, Mancini GB, Kuramoto L, et al. The prognostic importance of endothelial dysfunction and carotid atheroma burden in patients with coronary artery disease. J Am Coll Cardiol 2003;42:1037-43. 
35. Gan WQ, McLean K, Brauer M, et al. Modeling population exposure to community noise and air pollution in a large metropolitan area. Environ Res 2012;116:11-16.

36. Lenters V, Uiterwaal CS, Beelen R, et al. Long-term exposure to air pollution and vascular damage in young adults. Epidemiology 2010;21:512-20.

37. Johnson HM, Piper ME, Baker TB, et al. Effects of smoking and cessation on subclinical arterial disease: a substudy of a randomized controlled trial. PLoS ONE 2012;7:e35332.

38. Wilker EH, Mittleman MA, Coull BA, et al. Long-term exposure to black carbon and carotid intima-media thickness: the normative aging study. Environ Health Perspect 2013;121: 1061-7.

39. Painschab MS, Davila-Roman VG, Gilman RH, et al. Chronic exposure to biomass fuel is associated with increased carotid artery intima-media thickness and a higher prevalence of atherosclerotic plaque. Heart 2013;99:984-91.

40. Rivera M, Basagana X, Aguilera I, et al. Association between long-term exposure to traffic-related air pollution and subclinical atherosclerosis: the REGICOR study. Environ Health Perspect 2013;121:223-30.

41. Sun M, Kaufman JD, Kim SY, et al. Particulate matter components and subclinical atherosclerosis: common approaches to estimating exposure in a Multi-Ethnic Study of Atherosclerosis cross-sectional study. Environ Health 2013;12:39.

42. Bonner MR, Han D, Nie J, et al. Positional accuracy of geocoded addresses in epidemiologic research. Epidemiology 2003;14:408-12.

43. Xie SD, Zhang YH, Li Q, et al. Spatial distribution of traffic-related pollutant concentrations in street canyons. Atmos Environ 2003;37:3213-24.

44. Restrepo C, Zimmerman R, Thurston G, et al. A comparison of ground-level air quality data with New York State Department of Environmental Conservation monitoring stations data in South Bronx, New York. Atmos Environ 2004;38:5295-304.

45. Hystad PU, Setton EM, Allen RW, et al. Modeling residential fine particulate matter infiltration for exposure assessment. J Expo Sci Environ Epidemiol 2009;19:570-9.

46. Janssen NA, Hoek G, Brunekreef B, et al. Personal sampling of particles in adults: relation among personal, indoor, and outdoor air concentrations. Am J Epidemiol 1998;147:537-47.

47. Nethery E, Leckie SE, Teschke K, et al. From measures to models: an evaluation of air pollution exposure assessment for epidemiological studies of pregnant women. Occup Environ Med 2008;65:579-86.

48. Shanmugam N, Roman-Rego A, Ong $\mathrm{P}$, et al. Atherosclerotic plaque regression: fact or fiction? Cardiovasc Drugs Ther 2010;24:311-17. 